\title{
Christopher Brumfit award 2015
}

The Editor and Board of Language Teaching are pleased to announce that the winner of the 2015 Christopher Brumfit thesis award is Dr Armin Berger. The thesis was selected by an external panel of judges based on its significance to the field of second language acquisition, second or foreign language learning and teaching, originality and creativity, and quality of presentation.

Dr Berger's Ph.D. thesis was entitled Validating analytic rating scales: A multi-method approach to scaling descriptors for assessing academic speaking. The thesis examined the proficiency continuum operationalised by the Austrian English Language Teaching and Testing (ELTT) initiative in two analytic rating scales for the assessment of academic presentations and interactions. The findings indicate that validation procedures should be mapped onto theoretical models of performance assessment. At a more general level, the findings offer a specification of academic speaking, adding concrete details to the reference levels in the Common European Framework.

The external referees commented on 'a truly impressive piece of work both in terms of the meticulous care with which the reported study was carried out as well as the clear and reader-friendly way in which it was written up. The study was predominantly focussed on a local context, but the careful process used to validate and revise the ELTT scales should prove a model for other institutions to follow.' Dr Berger completed his thesis at the University of Vienna, Austria under the supervision of Dr Christiane Dalton-Puffer and Dr Günther Sigott.

This year's runner-up was Dr Amy Isabel Young, whose Ph.D. thesis was entitled Student oral proficiency in grade three Spanish immersion: Linguistic diversity, student interaction and differentiated scaffolding. The external referees praised a '... highly impressive, indeed quite outstanding, thesis. It is very well written, addresses a topic that is equally important for research, for policy and for teaching, and shows the writer to be in authoritative command of her subject, both in elaborating and making good use of theoretical concepts from a range of sources within the literature and in addressing practical matters of teaching, learning and interpersonal relations.' Dr Young read her thesis at the University of Minnesota (USA) and her advisors were Dr Tara Fortune and Dr Diane Teddick.

The Christopher Brumfit award will be presented in a new format from 2017. 